\title{
$\mathrm{IP}-$ 기반 고정형 VoIP 긴급통화 시스템 설계 및 구현
}

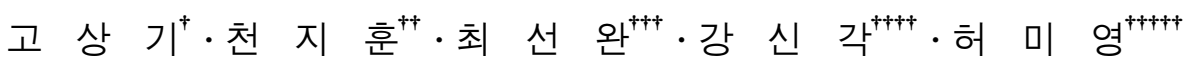

요 약

\begin{abstract}
VoIP 망에서 긴급통화 서비스는 기존의 유·무선 전화 서비스와 같이 필수 사항이다. 이를 지원하기 위한 표준화 작업이 활발히 진행되고 있으며, National Emergency Number Association (NENA)는 기존의 유·무선망에서의 긴급통화 서비스를 위한 프레임워크 및 프로시져를 개 발하고 있다. 반면에 Internet Engineering Task Force (IETF)에서는 착발신이 모두 IP 환경을 고려한 긴급통신 프로토콜에 초점을 두고 있다. 그 결과, 두 모델 간에 불일치가 발생한다. 본 논문에서는 이를 해결하기 위해, NENA 구조를 채택하여 수정하고, 수정된 모델에 IETF 프로토 콜을 적용할 수 있는 SIP 기반 VoIP 긴급통화 시스템을 설계하고 구현한다. 특히, 긴급 호를 다루는 재난방재센터 (PSAP, Public Safety Answering Point)는 기존 통신 환경 및 인터넷 환경 모두를 고려한다. 본 시스템은 유닉스 환경에서 구현된다.
\end{abstract}

키워드: VolP, 긴급통화, Session Initiation Protocol (SIP)

\section{Design and Implementation of an IP-based Fixed VoIP Emergency System}

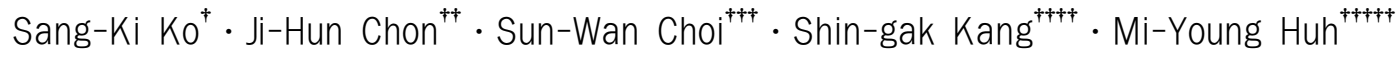

\begin{abstract}
An emergency service over Voice over IP (VoIP) network is an essential condition, like the existing telecommunication services. To support for the emergency services, standardization works have been performed. The National Emergency Number Association (NENA) has been developing the framework and procedures for an emergency service for Non-IP based network, rather than protocols. In contrast, the Internet Engineering Task Force (IETF) has been only focused on end-to-end IP-based emergency calls. The NENA architecture is incompatible with the IETF protocols. To solve the problem, we design and implement a SIP-based VoIP emergency system by adopting the NENA architecture and by applying IETF protocols, for both IP-based Pubic Safety Answering Point (PSAP) and PSTN-based PSAP. It is implemented and tested under UNIX environment.
\end{abstract}

Key Words: VolP, Emergency Call, Session Initiation Protocol (SIP)

\section{1. 서 론}

IP 기반의 통신서비스가 발달함에 따라, 인터넷 전화 (VoIP, Voice over Internet Protocol) 서비스는 새로운 통신 수단으로 인식되고 있다. 인터넷 전화 서비스는 기존의 통 신수단인 유-무선 전화 서비스와 비교하여 저렴한 통화료 와 우수한 통화품질이란 이점을 통해 앞으로도 지속적인 발 전을 거듭할 것이며 곧 기존의 통신수단을 대체할 것으로 기대한다.인터넷 전화 서비스가 기존의 통신수단을 대체한

\footnotetext{
† 준 회 워 : 광운대학교 전자통식공학과 박사과정

†† 준 회 원: 안양대학교 정보통신공학과 석사과점

†+† 정 회 원: 안양대학교 정보통신공학과 교수

††申† 종신회원 : 한국전자통신연구원 융합통신표준연구센터 팀장

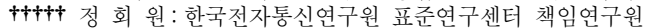
논문접수: 2008년 1월 4 일 수 정 일 : 2008 년 5 월 30 일 심사완료: 2008 년 6 월 5일
}

다는 의미는 기존의 통신수단에서 제공하는 모든 서비스를 인터넷 전화 서비스에서도 제공해야 하는 것을 말한다. 기 존의 통신수단에서 제공하는 서비스 중에서 대표적인 서비 스는 긴급통화 서비스이다.

긴급통화 서비스란 각종 재난으로부터 국민의 생명, 신체 및 재산을 보호하기 위해 긴급한 상황에 처한 국민들이 국 가에 도움을 요청할 수 있는 전화서비스이다. 예를 들어, 우 리나라에서는 국민의 생명, 신체, 재산의 보호, 범죄 예방 및 진압 등의 경찰의 도움이 필요할 경우, 경찰의 도움을 요청 할 수 있는 112 서비스와 화재 예방 및 진압, 인명구조 등의 소방 구조대의 도움이 필요할 경우, 소방 구조대의 도움을 요청할 수 있는 119 서비스가 있다.

기존의 통신수단인 유·무선 전화 서비스에서는 긴급한 상황에 처한 긴급통화 발신자가 112 또는 119 를 요청했을 때, 발신 지역에서 가장 가까운 경찰서나 소방서 등의 관할 
긴급구조기관으로 긴급통화가 연결된다. 이 때, 긴급구조기 관은 긴급통화 발신자의 전화번호와 위치(주소) 정보를 수 신하여 긴급통화 발신자가 자신의 위치 정보를 긴급구조기 관에게 알려줄 수 없는 상황에 처했을 때도 긴급통화 발신 자는 긴급구조기관으로부터 도움을 받을 수 있다. 하지만 현재의 인터넷 전화 서비스에서는 긴급통화 발신 지역에 따 라 자동으로 가장 가까운 경찰서나 소방서 등의 관할 긴급 구조기관으로 연결해 주는 근거리 라우팅 기능을 제공하지 못하는 기술적인 문제점으로 인하여 긴급통화 서비스를 제 공하지 않는다. 이는 앞으로 인터넷 전화 서비스가 새로운 통신수단으로 지속적인 발전을 거듭하는 데 문제점으로 작 용할 수 있다. 이에 따라, 인터넷 전화 서비스에서도 긴급통 화 서비스를 제공할 필요성이 제기된다. 본 논문에서는 인 터넷 전화 서비스에서 긴급통화 서비스를 제공할 수 있도록 VoIP 긴급통화 시스템을 제안하고 이를 구현한다. 이를 위 해, 인터넷 표준화 기구인 Internet Engineering Task Force (IETF)의 Emergency Context Resolution with Internet Technologies (ECRIT) [1]과 Geographic Location / Privacy (GEOPRIV) [2]워킹 그룹의 프로토콜을 연구하였다. 또한 북미의 긴급통화 서비스관련 단체인 National Emergency Number Association (NENA) [3]의 VoIP 긴급통화 서비스 기술을 연구하였다. 연구한 내용을 바탕으로 NENA 구조를 채택하여 수정하고, 수정된 모델에 IETF 프로토콜을 적용할 수 있는 SIP 기반 VoIP 긴급통화 시스템을 설계하고 이를 구현한다.

본 논문의 구성은 다음과 같다. 2장에서는 $\mathrm{NENA}$ 와 $\mathrm{IETF}$ 에서 진행 중인 $\mathrm{VoIP}$ 긴급통화 서비스 표준화 동향 및 관련 기술에 대하여 설명한다. 3 장과 4 장에 걸쳐 $\mathrm{VoIP}$ 긴급 통화 시스템 설계 및 구현에 대한 내용을 기술한다. 마지막 으로 5 장에서는 본 논문의 결론에 대하여 기술한다.

\section{2. 관련 연구}

현재 우리나라에 앞서 인터넷 전화 서비스를 제공하고 있 는 미국과 캐나다에서는 $\mathrm{VoIP}$ 긴급통화 서비스에 대한 연 구를 진행하고 있다. 미국의 연방통신위원회(FCC, Federal Communications Commission)와 캐나다의 라디오-TV 및 통 신위원회(CRTC, Canadian Radio-television and Telecommunication Commission)에서는 인터넷 전화 서비스 제공업체들에게 $\mathrm{VoIP}$ 긴급통화 서비스 제공 의무에 대한 고시(Order)를 하여 이들 국가에서는 정책적으로 $\mathrm{VoIP}$ 긴급 통화 서비스를 제공하고 있다 [4]. VoIP 긴급통화 서비스에 대한 표준화 동향 및 관련 기술은 $\mathrm{IETF}$ 의 ECRIT, GEOPRIV 워킹 그룹과 NENA에서 연구를 진행하고 있다. 다음은 이들 단체의 표준화 현황 및 관련 기술을 설명한다.

$\mathrm{NENA}$ 는 북미에서 긴급통화 서비스 (E911, Enhanced 911)를 효과적으로 제공하기 위해 결성된 단체이다. NENA 에서는 인터넷 전화 서비스에서 긴급통화 서비스를 지원하 기 위해, "I2" [5]와 "I3" [6] 기술을 연구하고 있다. "I2" 기
술은 기존의 유선 전화 서비스에서 사용하였던 Public Switched Telephone Network (PSTN) 기반의 긴급통화 시 스템 네트워크를 재사용하여 $\mathrm{VoIP}$ 긴급통화 발신자의 긴급 통화 호를 가장 가까운 관할 재난방재센터(PSAP, Public Safety Answering Point)로 전달해 주기 위한 프레임워크 (Framework) 및 프로시져(Procedure)를 정의한다. "I3" 기술 은 인터넷상에서 IP 기반의 긴급통화 시스템 네트워크를 전 제하여 인터넷 전화 서비스에서 긴급통화 서비스를 제공할 경우, PSTN 기반의 재난방재센터와 IP 기반의 재난방재센 터 환경을 모두 수용할 수 있는 $\mathrm{VoIP}$ 긴급통화 시스템을 위한 프레임워크 및 프로시져를 정의한다.

IETF ECRIT 워킹 그룹은 인터넷상에서 VoIP 긴급통화 발신자의 긴급통화 호를 가장 가까운 관할 재난방재센터로 전달하기 위해, 긴급통화 호 라우팅을 위한 기술을 연구하 고 있다. 이 그룹에서 연구하고 있는 기술은 인터넷상에서 긴급통화 호를 라우팅하기 위한 프레임워크, 긴급통화 발신 자 위치를 기준으로 가장 가까운 관할 재난방재센터로 긴급 통화 호를 전달하기 위한 매핑 기능을 정의한다 [7-12]. 또 한 긴급통화 서비스를 식별하기 위해, 서비스 Uniform Resource Name (URN) [7]을 정의하며 긴급통화 호 발신자 의 위치를 기준으로 가장 가까운 관할 재난방재센터를 검색 하는 매핑 기능을 제공하기 위해, Location-to-Service Translation Protocol (LoST) [8]을 정의한다. LoST 프로 토콜 기반의 매핑 서비스는 LoST 클라이언트가 LoST 서버 에게 긴급통화 호 발신자의 위치 정보와 서비스 $\mathrm{URN}$ 을 포 함한 쿼리 메시지를 요청할 경우, LoST 서버는 자신의 데 이터베이스에서 위의 두 가지 정보와 일치하는 하나 또는 그 이상의 재난방재센터 Uniform Resource Identifier (URI) 를 응답 메시지로 $\operatorname{LoST}$ 클라이언트에게 전달한다.

IETF GEOPRIV 워킹 그룹은 인터넷상에서 위치정보의 프라이버시(Privacy) 관리를 위한 데이터 형식을 연구하고 있다. 이 그룹에서 연구하고 있는 기술은 위치기반 긴급통 화 서비스를 제공하기 위해, 긴급통화 호 발신자의 위치정 보를 재난방재센터로 안전하게 전달하기 위한 요구사항을 정의하며 긴급통화 호 발신자의 위치정보는 위도(Latitude), 경도(Longitude), 고도(Altitude)로 표현되는 지리적 (geospatial) 위치정보와 일반 주소 표기법인 Civic 위치정보 로 표현한다. 긴급통화 호 발신자의 위치정보를 표현하는 객 체(Object)는 Presence Information Data Format (PIDF)를 확 장한 것이다 [13-15].

[16] 문서에서 Mintz-Habib가 제안한 $\mathrm{VoIP}$ 긴급통화 서비 스 구조는 긴급통화 호 식별, 긴급통화 발신자의 위치 결정, 긴급통화 호 근거리 라우팅을 고려하여 설계하였다. 다음의 (그림 1)은 Mintz-Habib가 제안한 긴급통화 서비스 시스템 구조를 보여준다.

(그림 1)의 구조에서는 Dynamic Host Configuration Protocol (DHCP) 서버를 이용하여 긴급통화 발신자(Caller) 의 위치정보를 결정하고 Domain Name System (DNS) 서 버를 이용하여 긴급통화 발신자의 위치를 기준으로 근거리 


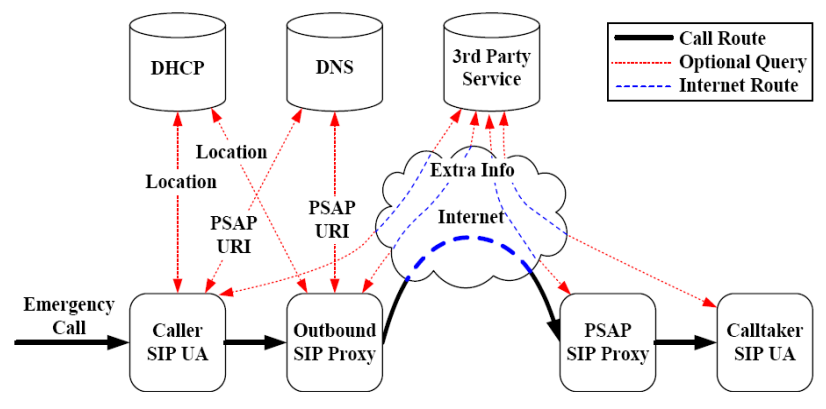

(그림 1) 긴급통화 서비스 시스템 구조 [16]

관할 재난방재센터를 찾는다. 이 구조는 기존의 DHCP 서버 와 DNS 서버의 역할을 확장한 것이다.

다음의 3 장에서는 본 논문에서 제안하는 $\mathrm{VoIP}$ 긴급통화 시스템에 대해 설명한다.

\section{VolP 긴급통화 시스템 설계}

VoIP 긴급통화 서비스는 인터넷 전화 사용자의 환경에 따라, 고정형 (fixed), 노메딕(nomadic), 이동형(mobile)으로 구분된다. 고정형 사용자는 현재 일반 가정의 유선 전화기 와 같은 단말기를 사용하는 고객으로 $\mathrm{VoIP}$ 단말기가 설치 될 경우, 설치된 장소에서 장기간 인터넷 전화 서비스를 제 공받는다. 이 경우, 사용자가 이사 등의 행위를 하지 않는 한은 사용자의 위치 정보가 변하지 않는다고 가정한다. 노 메딕 사용자는 데스크 IP 폰, USB 폰과 같은 단말기를 컴 퓨터에 연결하여 인터넷 전화 서비스를 제공받는다. 이 때, 사용자는 주간에는 회사에서, 야간에는 집에서 $\mathrm{VoIP}$ 단말기 를 컴퓨터에 연결하여 인터넷 전화를 사용할 수 있기 때문 에 한 장소에서 장기간 고정된 위치정보를 가지고 인터넷 전화를 사용할 수 없다. 따라서 인터넷 전화를 사용할 경우, 회사나 집 등의 고정된 위치환경에서 인터넷 전화 서비스를 제공받지만 인터넷 전화를 사용하는 장소에 따라, 사용자의 위치정보가 변하므로 고정형 사용자와는 다른 특징을 지닌 다. 이동형 사용자는 휴대폰과 같은 이동성(mobility)을 지닌 $\mathrm{VoIP}$ 단말기를 사용하는 고객으로 단말기의 특성상 사용자 의 위치정보는 인터넷 전화를 사용하는 중에도 변할 수 있 다. 이러한 특성에 따라, VoIP 긴급통화 시스템도 각각의 사용자 환경마다 다르게 설계해야 한다. 또한 재난방재센터 (PSAP)의 환경이 기존의 PSTN 기반의 긴급통화 시스템 네트워크인지, IP 기반의 긴급통화 시스템 네트워크인지에 따라서도 $\mathrm{VoIP}$ 긴급통화 시스템은 다르게 설계해야 한다. 다음은 각각의 사용자 환경에 따른 $\mathrm{VoIP}$ 긴급통화 시스템 에 대해 설명한다.

\section{1 고정형 VolP 긴급통화 시스템 [17]}

고정형 VoIP 긴급통화 시스템은 두 가지로 정의할 수 있 다. 하나는 기존의 PSTN 기반의 긴급통화 시스템 네트워크

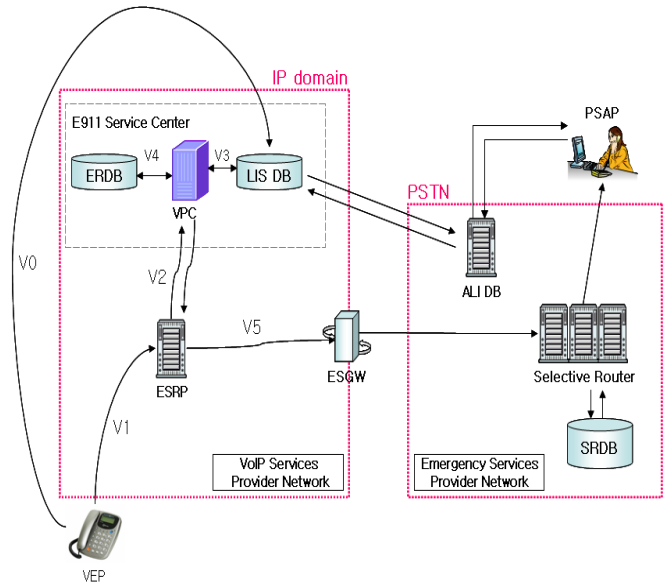

VEP : YolP EndPoint ESAP : Emergency Service Routing Proxy PSAP : Public Safety Answering Point VPC: VoIP Positioning Center LS DE : Location Information Server Database ESGW: Emergency Services GatelWay EFDB : ESZ Routing DataBase $A \triangle D B$ : Automatic Location Identification DataBase SRDB : Selective Routing DataBase

(그림 2) PSTN 기반 고정형 VoIP 긴급통화 시스템

를 이용한 경우이고 다른 하나는 IP 기반의 긴급통화 시스 템 네트워크를 이용한 경우이다. 다음의 (그림 2)는 IP 도메 인과 기존의 PSTN 기반의 긴급통화 시스템 네트워크를 연 동하여 고정형 $\mathrm{VoIP}$ 긴급통화 서비스를 지원하기 위한 PSTN 기반 고정형 VoIP 긴급통화 시스템 구성도이다.

위 시스템의 구성요소의 기능은 다음과 같다. 인터넷 전 화 단말기(VEP)는 긴급통화를 요청할 수 있는 VoIP 사용자 단말기로써, 위치정보서버 데이터베이스(LIS DB)로부터 위 치정보와 관련한 쿼리 키 값을 받는다. 긴급통화 서비스 라 우팅 프록시(ESRP)는 긴급통화를 식별하고 적절한 관할 재 난방재센터로 긴급통화 호를 전달한다. VoIP 위치확인 센터 (VPC)는 긴급통화 호의 라우팅을 지원하기 위해, 위치정보 서버 데이터베이스(LIS DB)와 긴급통화 서비스 라우팅 데 이터베이스(ERDB)와 연동하여 긴급통화 발신자의 위치정보 와 관련된 쿼리 키 값과 라우팅 경로를 선택하기 위한 라우 팅 번호 값을 생성하여 전달한다. 위치정보서버 데이터베이 스(LIS DB)는 인터넷 전화 가입자의 가입정보인 위치정보 (주소)와 전화번호를 저장하며 이 정보들과 고객마다 유일 하게 발급받은 쿼리 키 값을 매핑하여 저장한다. 긴급통화 서비스 라우팅 데이터베이스(ERDB)는 재난방재센터의 관할 구역마다 해당 관할 재난방재센터의 정보를 매핑하여 저장 하며 이 정보들은 특정 긴급통화 호를 어디로 라우팅할 것 인지 결정하는 데 중요한 역할을 한다. 긴급통화 서비스 게 이트웨이(ESGW)는 IP 도메인상의 시그널링을 PSTN 기반 의 긴급통화 시스템 네트워크로 전달한다. 셀렉티브 라우터 (Selective Router)는 셀렉티브 라우터 데이터베이스(SRDB) 와 연동하여 적절한 재난방재센터로 긴급통화 호를 전달한 다. 셀렉티브 라우터 데이터베이스(SRDB)는 재난방재센터 들의 위치정보와 전화번호를 매핑하여 저장하고 있다. 자동 위치 확인 데이터베이스(ALI DB)는 위치정보서버 데이터베 이스(LIS DB)와 연동하여 긴급통화 발신자의 위치정보와 전화번호를 저장한다. 


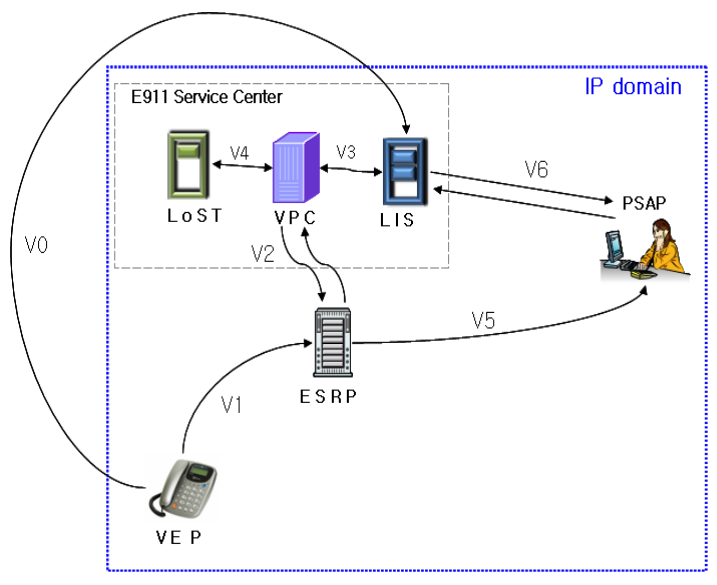

VEP : VolP EndPoint VPC : VolP Positioning Center LIS : Location Information Server

ESRP : Emergency Service Routing Proxy LOST : Location to Service Translation Server PSAP : Public Safety Answering Point

(그림 3) IP 기반 고정형 VolP 긴급통화 시스템

다음으로 IP 기반의 긴급통화 시스템 네트워크를 이용한 고정형 $\mathrm{VoIP}$ 긴급통화 시스템을 설명한다. (그림 3)은 IP 기반의 긴급통화 시스템 네트워크를 연동하여 고정형 $\mathrm{VoIP}$ 긴급통화 서비스를 지원하기 위한 IP 기반 고정형 $\mathrm{VoIP}$ 긴 급통화 시스템 구성도이다. 위 시스템의 일부 구성요소는 $\mathrm{PSTN}$ 기반 고정형 $\mathrm{VoIP}$ 긴급통화 시스템의 구성요소와 동 일한 기능을 수행함으로써 이들 구성요소는 PSTN 기반 고 정형 $\mathrm{VoIP}$ 긴급통화 시스템의 구성요소와 동일한 기능을 가진다. 다음으로, $\mathrm{LOST}$ 서버는 재난방재센터의 관할 지역 과 재난방재센터의 URI를 매핑하여 저장한다. 이 서버는 긴 급통화 발신자의 위치정보를 기준으로 가장 가까운 관할 재 난방재센터의 URI를 응답해 줌으로써 긴급통화 발신자의 긴급통화 호를 해당 관할 재난방재센터로 라우팅할 수 있도 록 결정하는 데 중요한 역할을 수행한다. 위치정보서버(LIS) 는 인터넷 전화 사용자의 위치정보(주소)와 전화번호를 매 핑하여 저장한다.

다음으로 노메딕 $\mathrm{VoIP}$ 긴급통화 시스템에 대해 설명한다. 노메딕 사용자가 인터넷 전화를 사용할 때에는 회사나 집 등의 고정된 위치환경이다. 그러므로 노메딕 사용자의 $\mathrm{VoIP}$ 긴급통화 시스템 구조는 고정형 사용자의 $\mathrm{VoIP}$ 긴급통화 시스템 구조와 동일하다. 따라서, 노메딕 $\mathrm{VoIP}$ 긴급통화 시 스템은 고정형 $\mathrm{VoIP}$ 긴급통화 시스템과 동일하게 설계할 수 있다. 이 때, 노메딕 사용자의 위치정보는 회사나 집 등 으로 변경될 수 있다. 따라서 노메딕 사용자는 $\mathrm{VoIP}$ 긴급통 화 서비스를 제공받기 위해, 변경된 자신의 위치정보를 스 스로 VoIP 서비스 제공업체에게 알려 주어야 한다. 이를 위 해, VoIP 서비스 제공업체는 (그림 4)와 같은 사용자 위치 정보 수정 방법을 노메딕 사용자에게 제공해야 한다.

이에, 본 논문에서는 위의 전제하에 노메딕 $\mathrm{VoIP}$ 긴급통 화 시스템 구성도를 위의 (그림 2)와 (그림 3)과 동일하게 설계한다.

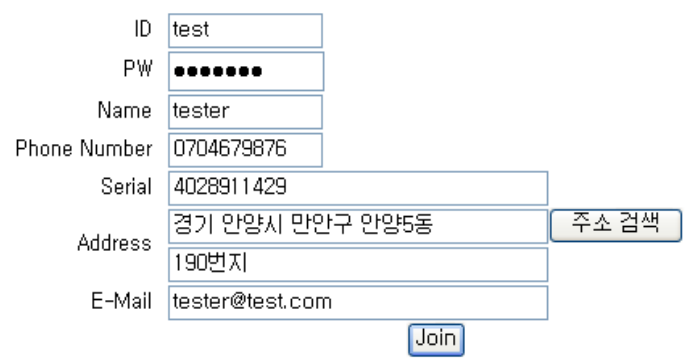

(그림 4) 위치 정보 수정 서비스

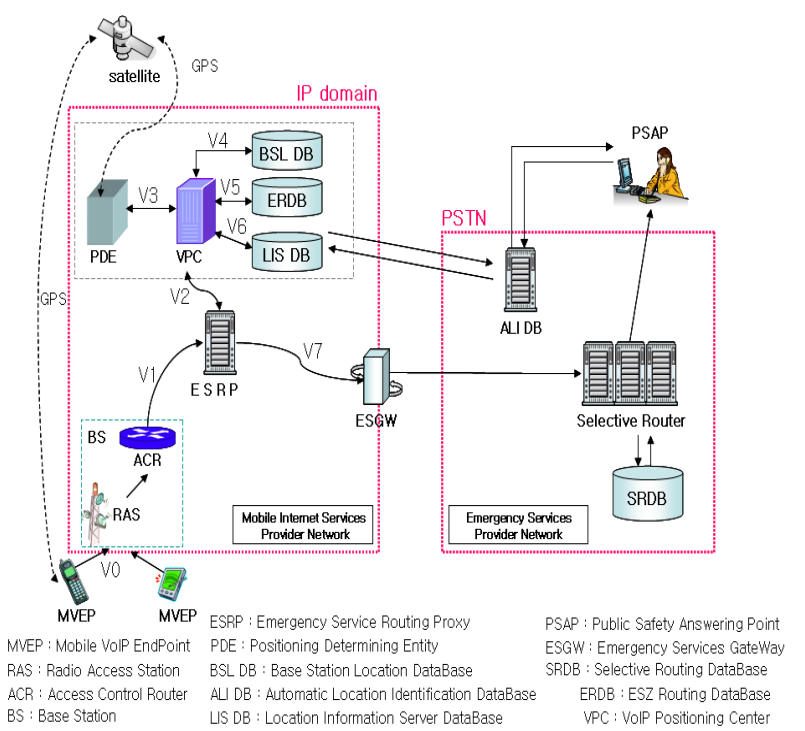

(그림 5) PSTN 기반 이동형 VoIP 긴급통화 시스템

3.2 이동형 VolP 긴급통화 시스템 [18]

이동형 $\mathrm{VoIP}$ 긴급통화 시스템도 고정형 $\mathrm{VoIP}$ 긴급통화 시스템과 같이, PSTN 기반과 IP 기반의 2가지 경우로 설계 한다. (그림 5)는 IP 도메인과 기존의 PSTN 기반의 긴급통 화 시스템 네트워크를 연동하여 이동형 $\mathrm{VoIP}$ 긴급통화 서 비스를 지원하기 위한 PSTN 기반 이동형 VoIP 긴급통화 시스템 구성도이다.

위 시스템의 일부 구성요소 또한 고정형 VoIP 긴급통화 시스템의 구성요소와 동일한 기능을 수행함으로써 이들 구 성요소도 고정형 $\mathrm{VoIP}$ 긴급통화 시스템의 구성요소와 동일 한 기능을 가진다. 다음으로, 기지국(BS)는 이동형 $\mathrm{VoIP}$ 사 용자의 단말기와 무선 접속하여 IP 주소 관리와 세션 관리 를 한다. 기지국을 식별할 수 있는 식별 플래그(flag)를 각각 의 기지국에 할당한다. 위치결정개체(PDE)는 GPS 기기와 연동하여 긴급통화 발신자 단말기의 지리적 위치정보를 측 위하는 기능을 수행하여 단말기의 위치를 결정한다. 기지국 위치정보 저장소(BSL $\mathrm{DB})$ 는 각각의 기지국의 식별 플래그 와 기지국의 위치정보를 매핑하여 이를 저장한다.

다음으로 IP 기반의 긴급통화 시스템 네트워크를 이용한 이동형 VoIP 긴급통화 시스템을 설명한다. (그림 6)는 IP 기반의 긴급통화 시스템 네트워크를 연동하여 이동형 $\mathrm{VoIP}$ 

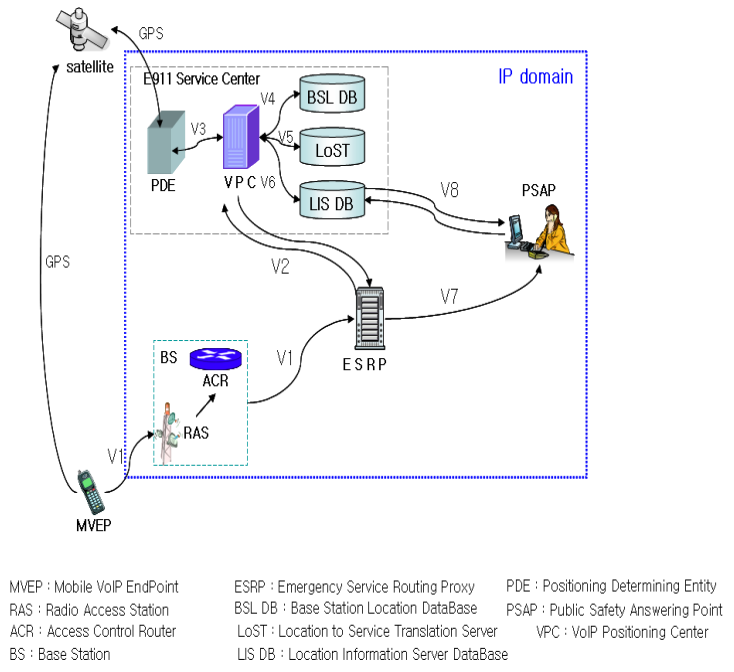

(그림 6) IP 기반 이동형 VolP 긴급통화 시스템

긴급통화 서비스를 지원하기 위한 IP 기반 이동형 VoIP 긴 급통화 시스템 구성도이다.

위 시스템의 구성요소는 (그림 3)과 (그림 5)에서 정의한 $\mathrm{VoIP}$ 긴급통화 시스템 구성요소와 동일한 기능을 수행하도 록 설계한다. 그러므로 이들 구성요소의 기능은 앞의 설명 을 참조한다.

\section{VoIP 긴급통화 시스템 구현}

본 장에서는 3장에서 설계한 $\mathrm{VoIP}$ 긴급통화 시스템들 중 에서 IP 기반 고정형 VoIP 긴급통화 시스템을 구현한다.

\section{1 구현 시스템 환경}

구현 및 테스트에 사용된 시스템은 Fedora Core 5 Linux 기반 Kernel 2.6에서 구현되었다. 인터넷 전화 단말기(VEP) 는 $\mathrm{C}^{++}$로 구현된 리눅스 기반의 VoIP 프로그램인 Kphone 을 사용하여 긴급통화 발신 기능을 추가하여 구현하였다. 긴급통화 서비스 라우팅 프록시(ESRP)는 $\mathrm{C}$ 언어로 구현된 IP 교환기(PBX, Private Branch Exchange)인 애스터리스크 (Asterisk)를 사용하여 긴급통화 호를 처리할 수 있는 기능 을 추가하여 구현하였다. 위치정보(주소)와 전화번호(콜백번 호), 재난방재센터(PSAP)의 관할 구역에 따른 관할 재난방 재센터의 URI 등의 매핑된 데이터들을 저장하는 데이터베 이스는 MySQL로 구현하였으며 위치정보를 Presence Information Data Format - Location Object (PIDF-LO) 형 태로 표현하여 전달하기 위해서, libxml을 사용하여 C언어 로 구현하였다.

\section{2 구현 모델}

본 장에서 구현한 IP 기반 고정형 $\mathrm{VoIP}$ 긴급통화 시스템의 구성도는 (그림 7)과 같고 $\mathrm{VoIP}$ 긴급통화 시스템 구성요소 간 의 긴급통화 호 라우팅 메시지 흐름도는 (그림 8)과 같다.

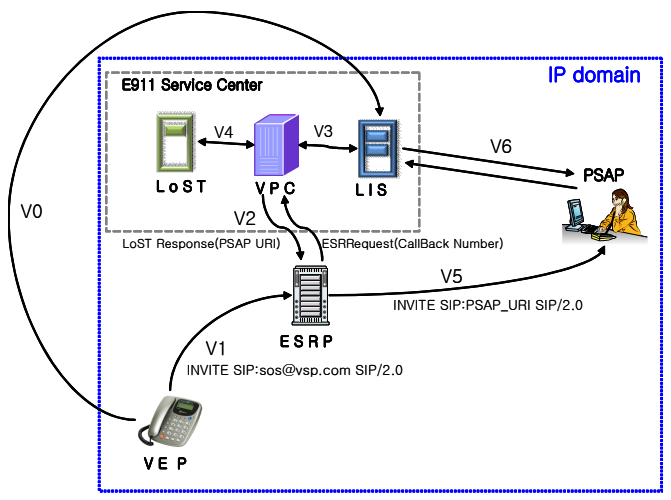

VEP : VoIP EndPoint

VPC : VoPP Pos lining Center US : Location Information Server

ESRP : Emergency Service Routing Proxy LoST : Location to Service Translation Server

(그림 7) 구현한 VolP 긴급통화 시스템의 구성도

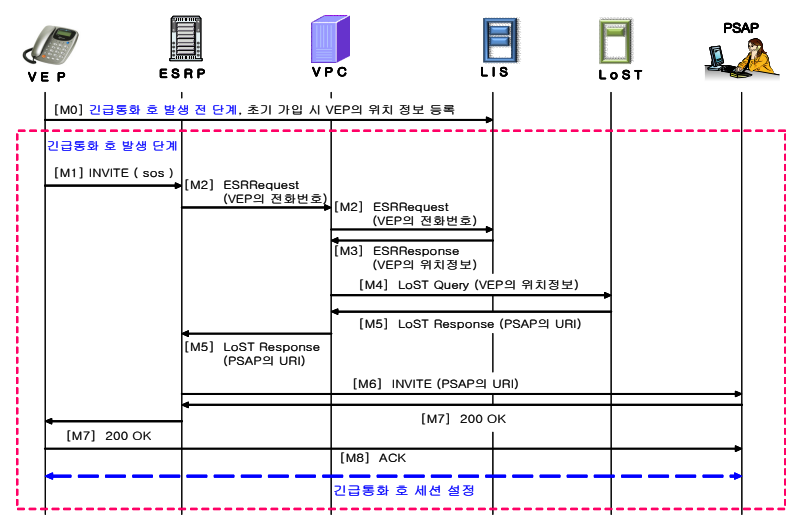

(그림 8) 긴급통화 호 라우팅 메시지 흐름도

〈표 1〉긴급통화 호의 To와 From 필드

\begin{tabular}{|c|c|}
\hline 헤더필드 & 헤더필드 값 \\
\hline To & sos@voipserviceprovider.com \\
\hline From & 0701234567@voipserviceprovider.com \\
\hline
\end{tabular}

인터넷 전화 사용자가 인터넷 전화 서비스 제공업체에 초 기 가입 시, 인터넷 전화 사용자의 위치정보(주소)는 인터넷 전화 서비스 제공업체의 위치정보서버(LIS)에게 등록된다. 이후 긴급통화가 발생할 때, 인터넷 전화 단말기(VEP)는 SIP From 헤더 필드 값으로 긴급통화 발신자의 전화번호를 지정하고 $\mathrm{SIP}$ To 헤더필드 값으로 긴급통화 호를 식별할 수 있는 문자열을 지정한다. 다음의 <표 $1>$ 은 긴급통화 호 [M1] 메시지의 To 필드와 From 필드의 예를 나타낸다.

긴급통화 서비스 라우팅 프록시 $(\mathrm{ESRP})$ 는 긴급통화 발신 자의 From 필드에 있는 발신자 전화번호를 이용하여 $\mathrm{VoIP}$ 위치확인 센터(VPC)에게 긴급통화 호 라우팅 정보를 요청 하는 Emergency Services Routing Request (ESRRequest) 메시지를 전달한다. $\mathrm{VoIP}$ 위치확인 센터(VPC)는 긴급통화 발신자의 위치정보와 전화번호를 매핑하여 저장하고 있는 위치정보서버(LIS)에게 이 메시지를 전달하여 긴급통화호 발신자의 전화번호와 일치하는 위치정보를 응답받는다. 
〈표 2〉 LIS의 데이터베이스 정보

\begin{tabular}{|c|c|c|c|}
\hline & 사용자 전화번호 & 사용자 주소 & $\cdots$ \\
\hline \hline 1 & $070-467-9876$ & 경기도 안양시 만안구 안양5동 190번지 & $\cdots$ \\
\hline 2 & $070-237-9876$ & 경기도 수원시 권선구 세류2동 1153번지 & $\cdots$ \\
\hline 3 & $070-396-9876$ & 경기도 군포시 산본1동 1105번지 & $\cdots$ \\
\hline 4 & $\cdots$ & $\cdots$ & $\cdots$ \\
\hline
\end{tabular}

〈표 3〉LOST의 데이터베이스 정보

\begin{tabular}{|c|c|c|}
\hline & PSAP의 관할 구역 & PSAP URI \\
\hline \hline 1 & 경기도 안양시 & 0314670119@psap.com \\
\hline 2 & 경기도 군포시 & 0313970119@psap.com \\
\hline 3 & 경기도 파주시 & 0319520119@psap.com \\
\hline 4 & $\cdots$ & $\cdots$ \\
\hline
\end{tabular}

<표 2>는 위치정보서버(LIS)에 저장되어 있는 인터넷 전 화 사용자의 전화번호와 위치정보의 예를 보여준다. $\mathrm{VoIP}$ 위치확인 센터 $(\mathrm{VPC})$ 는 긴급통화 호 발신자의 위치정보를 이용하여 LoST 서버에게 관할 재난방재센터(PSAP)의 URI 를 요청하는 쿼리 메시지를 전달하여 위치정보에 알맞은 재 난방재센터의 URI를 응답받는다. 다음의 <표 3>은 LoST 서버에 저장되어 있는 재난방재센터의 관할 구역에 따른 재 난방재센터의 URI 예를 보여준다.

다음으로 $\operatorname{LoST}$ 쿼리 메시지와 LoST 응답 메시지에 대 해 설명한다. LoST 쿼리 메시지는 긴급통화 발신자의 위치 정보 중에서 <A1>형식부터 <A3>형식까지의 위치정보를 사용한다. 그 이유는 재난방재센터의 관할 구역의 위치정보 가 <A3>형식인 '동' 단위로 구분되기 때문이다. 따라서 $\operatorname{LoST}$ 응답 메시지는 $<\mathrm{A} 1>$ 형식부터 $<\mathrm{A} 3>$ 형식까지의 위치 정보와 매핑하는 재난방재센터의 URI를 찾아 응답해 준다. 이들 메시지를 통해 긴급통화 발신자의 위치정보를 기준으 로 가장 가까운 관할 재난방재센터의 URI를 얻는다. 다음의 (그림 9)는 LoST 쿼리 메시지를, (그림 10)은 LoST 응답 메시지를 보여준다.

이 단계를 마치면, 최종적으로 긴급통화 서비스 라우팅 프록시(ESRP)는 LoST 서버의 응답 메시지에 포함된 재난 방재센터의 URI로 긴급통화 호를 전달하여 성공적으로 긴 급통화 호 세션 설정을 끝마치게 된다.

다음으로 구현한 시스템을 시험하였다. (그림 11)는 구현 한 시스템을 시험하기 위한 시험 구조도를 나타낸다. (그림 11)의 시험 시나리오는 안양5동 위치정보를 가지고 있는 인 터넷 전화 단말기 $(\mathrm{VEP} 1)$ 와 산본1동 위치정보를 가지고 있 는 인터넷 전화 단말기(VEP2)에서 긴급통화 호를 발신했을 때, 인터넷 전화 단말기의 위치정보를 기준으로 가장 가까 운 관할 재난방재센터로 긴급통화 호가 정확히 라우팅되는 지 시험하였다.

100 회의 시험을 수행한 결과, 안양5동 위치정보를 가지고 있는 인터넷 전화 단말기(VEP1)에서 발신한 긴급통화 호는 안양 5 동을 관할하는 재난방재센터로 $100 \%$ 정확히 라우팅 되었으며 산본1동 위치정보를 가지고 있는 인터넷 전화 단

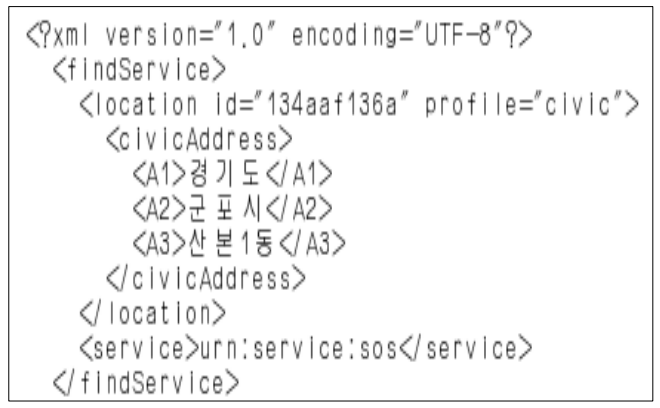

(그림 9) LOST 쿼리 메시지

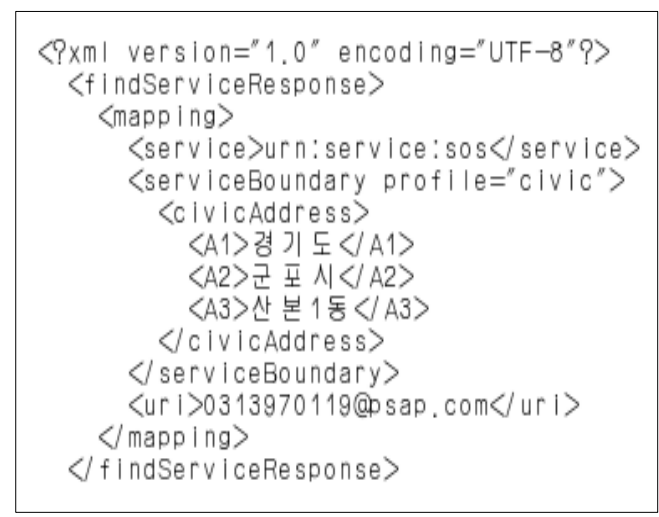

(그림 10) LOST 응답 메시지

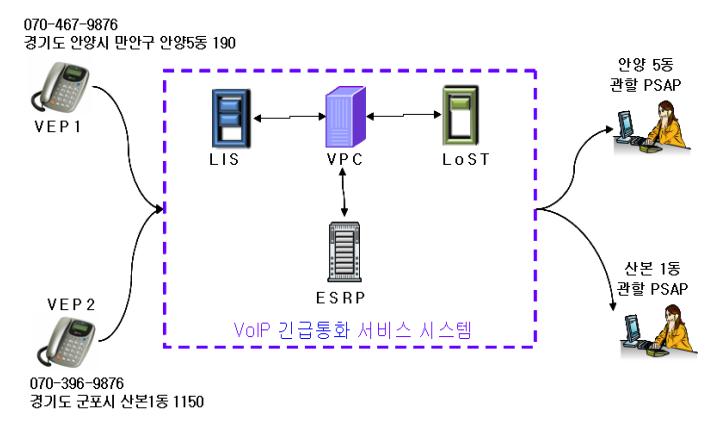

(그림 11) 시험 구조도

말기(VEP2)에서 발신한 긴급통화 호도 산본1동을 관할하는 재난방재센터로 $100 \%$ 정확히 라우팅 되는 것을 확인하였다. 다음으로 구현한 긴급통화 시스템의 처리율(Throughput)과 지연시간(Delay)을 측정하였다. 시스템의 처리율은 초당 처 리할 수 있는 긴급통화 호의 수를 의미한다. 로컬 네트워크 환경에서 펜티엄 $4(\mathrm{CPU}: 2.0 \mathrm{GHz}, \mathrm{RAM}: 1 \mathrm{~GB})$ 성능의 긴급통화 시스템을 사용하여 측정한 결과, 시스템의 처리율 


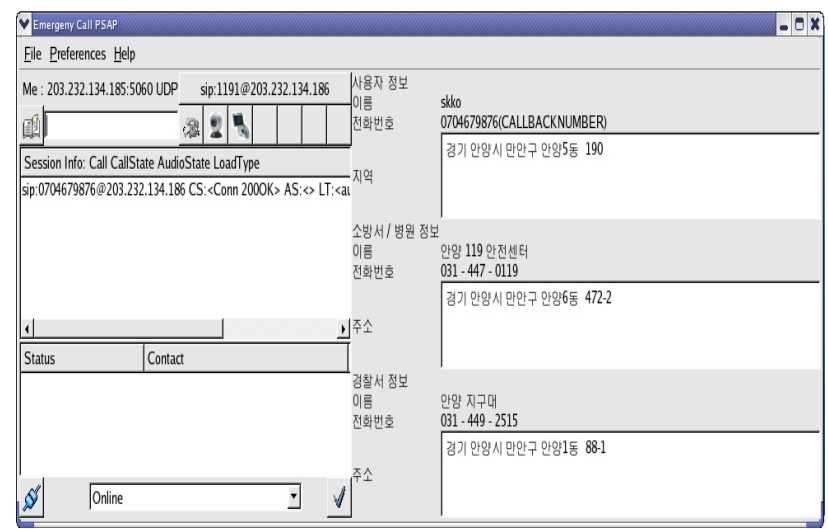

(그림 12) 안양5동 관할 재난방재센터

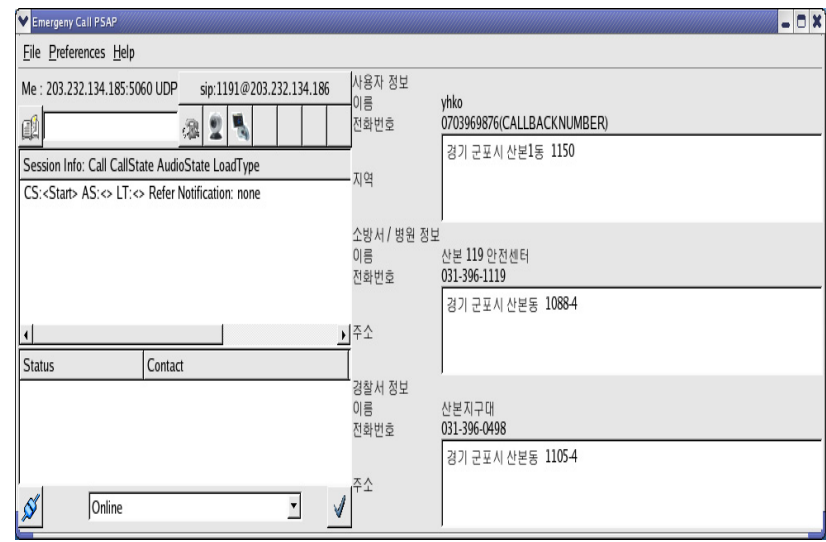

(그림 13) 산본1동 관할 재난방재센터

은 $10 \mathrm{c} / \mathrm{s}($ call per second), 지연시간은 평균 $50 \mathrm{~ms}$ 의 측정 결 과를 얻었다.

다음의 (그림 12)는 안양5동 위치정보를 가지고 있는 인 터넷 전화 단말기(VEP1)에서 발신한 긴급통화 호를 수신한 안양5동 관할 재난방재센터의 정보를 나타낸다.

다음의 (그림 13)는 산본1동 위치정보를 가지고 있는 인 터넷 전화 단말기(VEP2)에서 발신한 긴급통화 호를 수신한 산본1동 관할 재난방재센터의 정보를 나타낸다.

위의 (그림 12)과 (그림 13)는 긴급통화 발신자의 위치정 보를 기준으로 가장 가까운 소방서와 경찰서의 이름, 전화 번호, 주소정보를 알려주는 관할 재난방재센터(PSAP)를 보 여준다. 시험은 재난방재센터의 관할 구역을 안양시와 군포 시를 대상으로 진행하였다.

\section{5. 결 론}

VoIP 망에서 긴급통화 서비스는 기존의 유-무선 전화 서비스와 같이 필수 사항이다. 이에, 본 논문에서는 $\mathrm{VoIP}$ 망에서 긴급통화 서비스를 제공할 수 있도록 VoIP 긴급통 화 시스템을 제안하였고 이를 구현하였다. 제안하는 모델은 NENA의 VoIP 긴급통화 구조를 채택하여 수정하고, 수정된
모델에 IETF의 긴급통신 프로토콜을 적용하였다. 이를 위 해, NENA와 IETF의 ECRIT, GEOPRIV 워킹 그룹에서 연 구를 진행 중인 $\mathrm{VoIP}$ 긴급통화 서비스 표준화 동향 및 관 련 기술을 분석하였다. 또한 구현한 VoIP 긴급통화 시스템 이 정상적으로 동작하는지 시험하였고 정상적으로 동작하는 것을 확인하였다.

본 논문에서 구현한 $\mathrm{VoIP}$ 긴급통화 시스템은 이동성 (mobility)을 지닌 단말기에 대해서는 고려하지 않았다. 향후 이동성을 지닌 단말기를 사용하는 인터넷 전화 사용자에게 도 긴급통화 서비스를 제공할 수 있도록 이동형(mobile) VoIP 긴급통화 시스템에 대한 연구를 진행할 것이다.

\section{참 고 문 헌}

[1] IETF ECRIT WG 홈페이지, http://www.ietf.org/ html.charters/ecrit-charter.html.

[2] IETF GEOPRIV WG 홈페이지, http://www.ietf. org/html.charters/geopriv-charter.html.

[3] NENA 홈페이지, http://www.nena.org.

[4] 허미영외 2인, "미국의 VoIP 긴급통화 정책 동향", 전자통 신동향분석, 제22권 제 1 호, pp.140-150, 2007.

[5] NENA, "08-001 Interim VoIP Architecture for Enhanced 911 Services (i2)," Dec. 2005.

[6] NENA, "08-751 i3 Technical Requirements Document," Sep. 2006.

[7] H. Schulzrinne, "A Uniform Resource Name (URN) for Emergency and Other Well-Known Services," draft-ietf-ecrit-service-urn-07.txt, Aug. 2007.

[8] T. Hardie and et. Al, "LoST : A Location-to-Service Translation Protocol," draft-ietf-ecrit-lost-06.txt, Aug. 2007.

[9] H. Schulzrinne and et. Al, "Requirements for Emergency Context Resolution with Internet Technologies," draft-ietf-ecrit-requirements-13.txt, Mar. 2007.

[10] H. Schulzrinne, "Location-to-URL Mapping Architecture and Framework," draft-ietf-ecrit-mapping-arch-03.txt, Sep. 2007.

[11] B. Rosen and et. Al, "Best Current Practice for Communications Services in support of Emergency Calling," draft-ietf-ecrit-phonebcp-02.txt, Sep. 2007.

[12] B. Rosen and et. Al, "Framework for Emergency Calling using Internet Multimedia," draft-ietf-ecrit-framework-03.txt, Sep. 2007.

[13] J. Peterson, "A Presence-based GEOPRIV Location Object Format," RFC 4119, Dec. 2005.

[14] H. Tschofenig and et. Al, "Carrying Location Objects in RADIUS and Diameter," draft-ietf-geopriv-radius-1o-16.txt, Aug. 2007.

[15] M. Thomson and et. Al, "Revised Civic Location Format for PIDF-LO," draft-ietf-geopriv-revised-civic-1o-06.txt, Oct. 2007. 
[16] M. Mintz-Habib and et. Al, "A VoIP Emergency Services Architecture and Prototype," in Proceeding of the 14th International Conference on Computer Communications and Networks, pp.523-528, Oct. 2005.

[17] 조현식외 7인, “고정형 $\mathrm{VoIP}$ 긴급통화 시스템의 구현”, 한국정보 처리학회 춘계학술발표대회 논문집, 제14권 제1호, pp.1327-1330, 2007.

[18] 고상기외 4인, "이동형 인터넷전화 긴급통화 서비스 모델 설

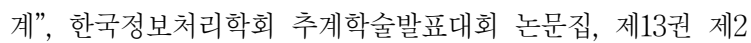
호, pp.1363-1366, 2006

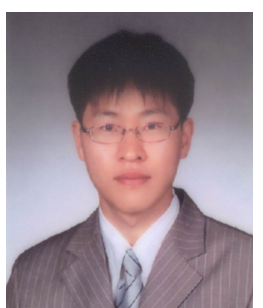

\section{고 상 기}

e-mail:skko@adams.kw.ac.kr

2006년 안양대학교 정보통신컴퓨터공학부 (학사)

2008년 안양대학교 정보통신공학과(석사) 2008년 현 재 광운대학교 전자통신공학과 (박사과정)

관심분야: SIP, VoIP, IPTV, QoS

\section{천 지 훈}

e-mail : jhchon@peacesoft.anyang.ac.kr 2008년 안양대학교 정보통신컴퓨터공학부 (학사)

2008년 현 재 안양대학교 정보통신공학과 (석사과정)

관심분야 : $\mathrm{VoIP}$, 네트워크 보안

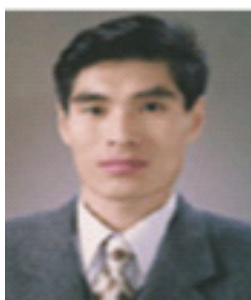

최 선 완

e-mail : sunchoi@anyang.ac.kr 1984년 홍익대학교 전자계산학과(학사) 1986년 한국과학기술원 전산학과(석사) 1996년 한국과학기술원 전산학과(박사) 1996년 현 재 안양대학교 정보통신공학과 교수

관심분야 : $\mathrm{VoIP}$, 위치정보시스템, 긴급통화

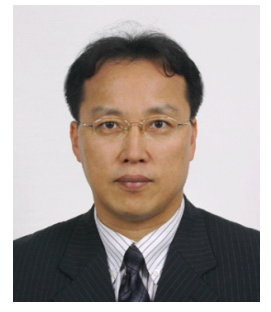

강 신 각

e-mail : sgkang@etri.re.kr

1984 충남대학교 전자공학과(학사)

1998 충남대학교 전자공학과(박사)

1995 정보통신기술사

1984 현 재 한국전자통신연구원 융합통신표준연구센터 팀장

1997 현 재 ITU-T Q.1/17 Rapporteur 2000 현 재 인터넷텔레포니포럼 부의장 관심분야 : 멀티캐스트, MoIP, IPTV, 미래인터넷

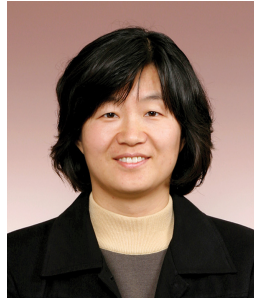

허 미 영

e-mail : myhuh@etri.re.kr 1990년 홍익대학교 컴퓨터공학과(학사) 2004년 충남대학교 정보통신공학과(석사) 1990년 현 재 한국전자통신연구원 표준연구센터 책임연구원 관심분야 : SIP, VoIP, IMS, 긴급통신 